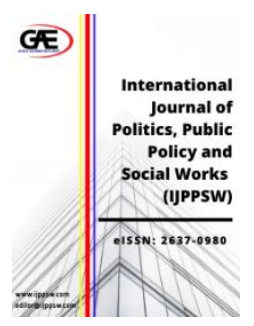

\author{
International Journal of Politics, Publics \\ Policy and Social Works (IJPPSW) \\ Journal Website: http://ijppsw.com/ \\ eISSN: 2637-0980
}

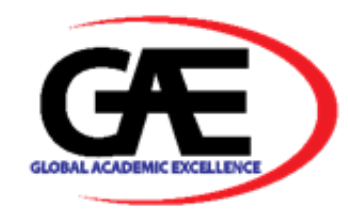

\title{
UNDERSTANDING THE CONCEPT OF POLICY TRANSFER: A SYSTEMATIC LITERATURE REVIEW APPROACH
}

\author{
Khairiah Salwa Mokhtar ${ }^{1}$, Nurulhasanah Abdul Rahman ${ }^{2 *}$ \\ 1 Department of Political Science, School of Distance Education, Universiti Sains Malaysia, Malaysia \\ Email: khairiah@usm.my \\ 2 Department of Political Science, School of Distance Education, Universiti Sains Malaysia, Malaysia \\ Email: hasanah.rahman89@yahoo.com \\ * Corresponding Author
}

\section{Article Info:}

Article history:

Received date:28.01.2020

Revised date: 28.04 .2020

Accepted date: 30.04 .2020

Published date: 10.06 .2020

\section{To cite this document:}

Mokhtar, K. S., \& Rahman, N. A. (2020). Understanding the Concept of Policy Transfer: A Systematic Literature Review Approach. International Journal of Politics, Publics Policy and Social Works, 2 (5), 01-13.

DOI: 10.35631/IJPPSW.25001.

\begin{abstract}
:
Policy transfer is not a new concept in public policy or political science research. However, there are many misconceptions about policy transfer from past scholars which fragmented policy understanding among political scientists and researchers. Hence, this paper aims to shed light on the basic concept of policy transfer and add value to the current literature especially in an academic context. This paper employed secondary data from the past ten years (2010-2020) derived from selected published resources of reputable databases specifically Scopus and ScienceDirect. There are four main stages in Systematic Literature Review (SLR) namely; (1) Pre-SLR, (2) Identification, (3) Screening, and (4) Eligibility. After considering the relevant articles from prior searching activities, 15 articles were reviewed systematically. Accordingly, five themes emerged to conclude the concept of policy transfer based on thematic analysis. This paper concludes with a summary of policy transfer discussion for future research and implications for policymakers were presented.
\end{abstract}

\section{Keywords:}

Policy Transfer, Policy Actors, Malaysia, Public Policy, Systematic Literature Review (SLR), Government

\section{Introduction}

For more than 30 years, publications on policy transfer had emerged from establishing the concept of policy transfer to the applications of policy transfer around the globe (Rose, 1991; Dolowitz, 2017; Zhang \& Yu, 2019). In the year 2019 per se, more researchers are discussing the use of policy transfer in modern perspective which not only concentrating on government policy but also in terms of private sector practices conducted by numerous countries in diverse fields. Among the scholarly efforts detailing the current process and actors involved Copyright $\odot$ GLOBAL ACADEMIC EXCELLENCE (M) SDN BHD - All rights reserved 
in policy transfer within different political context and knowledge segments includes the work by Crossley (2019) on comparative education and sustainability; Freestone and James (2019) on urban city planning; Jones, Blaustein, and Newburn (2019) on criminology; as well as Bertram, Maleki, and Karsten (2019) on private sponsorship schemes, among others.

Further, some scholars are actually discussing the concept of policy transfer without realising it. For instance, in Malaysian context, Zainol, Jusop, Ridzuan, and Kamaruddin (2019) described the Malaysian border issues and the authors proposed suggestions to the government to employ the Coordinated Border Management (CBM) approach. This approach was taken from European experience in securing their international borders. The act to resolve domestic issue by referring to international solutions is definitely among the underlying concept of policy transfer. In the same vein, Othman (2019) affirmed that higher education sector requires a vast transformation as good as economic revolution by looking at Economic Transformation Plan (ETP) in Malaysia. With the aim to internationalize Malaysian higher education, the education sector draws lessons from ETP which defined the voluntary transfer of ideas from different sectors within a similar political context which defined a part of policy transfer approach. Despite extensive research on policy transfer, the issue of adherence to policy transfer conditions and its complexity are raised and the core concept to understand policy transfer is often overlooked (Dolowitz, 2017). In fact, the effort to systematically review the recent policy transfer studies is relatively scarce. The definitions and components of policy transfer are varied and mostly unclear (Crossley, 2019; Freestone \& James, 2019). Different studies described different connotations of policy transfer approach thus leading to confusion among academicians and policymakers. Working upon this gap, the present study decided to conduct systematic review to understand the concept of policy transfer due to several reasons.

First, this review strengthened previous work by adopting a systematic procedure in searching and retrieving recent publications to ensure transparency with a wider area of research. Second, the selection of articles is based on restricted inclusion and exclusion criteria which allows the researchers to cope with research bias and more accurate results can be achieved according to research objective. As a result, this paper adds value to the existing literature by systematically review relevant articles based on systematic procedures from keywords identification to articles eligibility analysis (Moher, Liberati, Tetzlaff, Altman, \& The PRISMA Group, 2009; Shaffril, Samah, Samsuddin, \& Ali, 2019). The development of this systematic review works upon the research objectives to shed lights on the understanding of policy transfer and identify significant themes (concepts) reflecting the practice of policy transfer regardless of its origin and receiving countries. At the end of this review, recommendations were proposed for future policy studies aiming to develop a more integrated research agenda on policy transfer. In terms of implications for policy makers, this review offers a reliable evidence-based framework and knowledge base as guidance in understanding the basic concept of policy transfer.

The remainder of this article are as follows: (1) The methodology section details out the specific method to retrieve articles based on four stages, followed by data analysis technique; (2) Results and discussion were provided according to themes emerged from systematic review; and (3) Limitations and recommendations were proposed for future research direction. It is imperative to note that, since this study employed systematic review, thus, the literature review section is omitted because the review will be presented in the results and discussion part (Shaffril et al., 2019). 


\section{Methodology}

This paper was guided by the Preferred Reporting Items for Systematic Reviews and MetaAnalyses (PRISMA). PRISMA is a published standard which allows rigorous search to conduct a systematic literature review (SLR). Most often, PRISMA acts as guidance for the researchers to include necessary information by specifying a set of items for reporting a comprehensive systematic review (Moher et al., 2009; Shaffril et al., 2019). Basically, this study adopted four stages of systematic review namely; Pre-SLR, Identification, Screening, and Eligibility.

\section{Pre-SLR}

This stage focuses on developing specific research questions and validating resources. Research questions for this paper are as follows: (1) What are the basic components to understand policy transfer? (2) How researchers defined policy transfer?, and (3) What are the significant themes/concepts related to the practice of policy transfer?. The resources referred to the databases used to search for literature related to the area of policy transfer. It is widely accepted that Scopus and Emerald Insight are among the established and robust databases. Scopus is the largest citation database for peer-reviewed research with more than 24,600 articles from 5,000 publishers (Scopus, 2020) whereas Emerald Insight covered over 255,000 articles from 300 journals (Emerald Insight, 2020). The use of more than one database is recommended to increase the likelihood of obtaining appropriate and relevant articles (Bramer, Rethlefsen, Kleijnen, \& Franco, 2017).

\section{Identification}

Identification is essentially the first step in systematic review process. The initial idea of identification is to determine the right keywords and develop the search string. In simple words, the researcher searches all relevant keywords related to the research topic simultaneously in both databases. In accordance with previous studies on systematic review, the keywords used might be from thesaurus, variations, related terms, expert opinions, or keywords from past literature (Moher et al., 2009; Bramer et al., 2017; Shaffril et al., 2019). In this study, the keywords used were: Policy Transfer, Policy Borrow*, Policy Converg*, Lesson Draw*, Public Policy, and Government. The asterisk (*) sign indicates the searching technique referred as Truncation to identify keywords with various word endings and spelling with the aim to broaden the search results (MIT Libraries, 2020). Accordingly, the search strings developed from Scopus and Emerald Insight was established in January 2020 (see Table 1). At this stage, there were 86,879 articles derived from the basic search and 1,590 articles were successfully retrieved using the advanced search from both databases.

Table 1: The Search String

\begin{tabular}{|c|c|c|}
\hline Database & Basic search & Advanced Search / Search String \\
\hline Scopus & $\begin{array}{l}\text { Policy Transfer } \\
\quad(n=29,879)\end{array}$ & $\begin{array}{l}\text { Title-Abs-Key (("Policy Transfer" OR "Policy Borrow*" } \\
\text { OR ("Policy Converg*") "OR "Lesson Draw*") AND } \\
\text { NOT ("Public Policy") AND government): } \mathrm{n}=590\end{array}$ \\
\hline $\begin{array}{l}\text { Emerald } \\
\text { Insight }\end{array}$ & $\begin{array}{c}\text { Policy Transfer } \\
(\mathrm{n}=57,000)\end{array}$ & $\begin{array}{l}\text { "Policy Transfer" OR "Policy Borrow*" OR ("Policy } \\
\text { Converg*") OR "Lesson Draw*" AND NOT "Public } \\
\text { Policy" AND government: } \mathrm{n}=1,000\end{array}$ \\
\hline
\end{tabular}

Total 86,879 articles $\quad 1,590$ articles

Source: Scopus (2020); Emerald Insight (2020) 


\section{Screening}

The screening process was conducted by determining the inclusion and exclusion criteria with the aim to remove any irrelevant or duplicate articles. At first, all articles were collated and reviewed in Microsoft Excel worksheet to remove identical articles (Bree \& Gallagher, 2016). At this point, out of 1,590 articles from the advanced search, 700 articles were removed. Then, the process was refined by re-evaluating the articles based on research questions and unrelated articles were excluded (Shaffril et al., 2019). From there, the researchers selected a number of inclusion parameters such as timeline (years), subject area, document type, source type, language, and access type as the search configurations as stated in Table 2. Overall, a total of 66 articles were retained after elimination process.

Table 2: The Search Configuration

\begin{tabular}{ccc}
\hline Criteria & Inclusion & Exclusion \\
\hline Years & $2010-2020$ & Publications before 2010 \\
Subject area & Social Sciences & Other than Social Sciences \\
Document Type & Articles & Other than articles \\
Source Type & Journals & Other than journals \\
Language & English & Non-English \\
Access Type & Open Access & Other than open access \\
\hline Total articles & Scopus $(\mathbf{n}=39)$ & Emerald Insight $(\mathbf{n}=\mathbf{2 7})$ \\
\hline
\end{tabular}

Source: Scopus (2020); Emerald Insight (2020)

\section{Eligibility}

The remaining articles $(\mathrm{n}=66)$ were manually sorted based on eligibility criteria (Scopus: $\mathrm{n}=39$; Emerald Insight, $\mathrm{n}=27$ ). At this stage, all articles were examined thoroughly to assess its content and quality as well as to ensure the papers are precisely selected based on predetermined criteria as decided earlier (Bramer et al., 2017; Shaffril et al., 2019). The final articles were reviewed carefully one by one to ensure the articles are worthy and capable to achieve the research objectives. There are 51 articles were rejected since this paper focused on the theory and concept of policy transfer in general than its application. At the final part, 15 articles were found to be relevant and ready for further analysis (see Figure 1). 

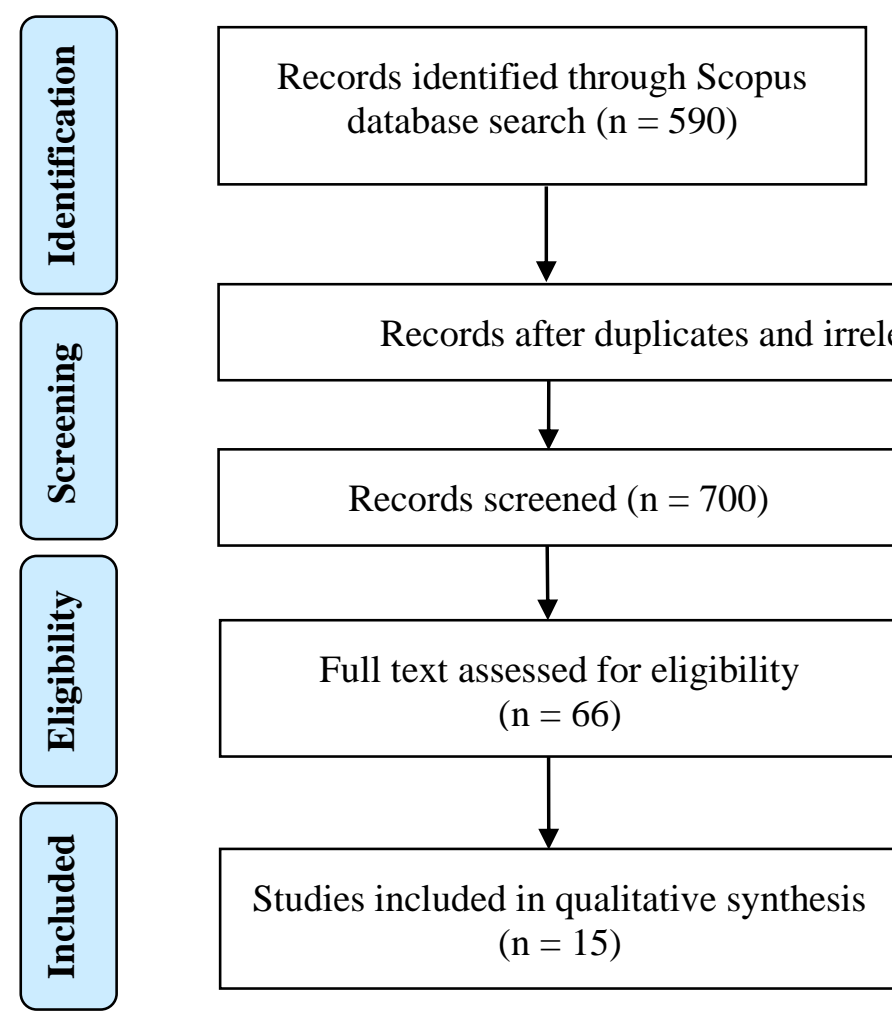

Records identified through Emerald database search $(n=590)$

Insight database search $(\mathrm{n}=1,000)$

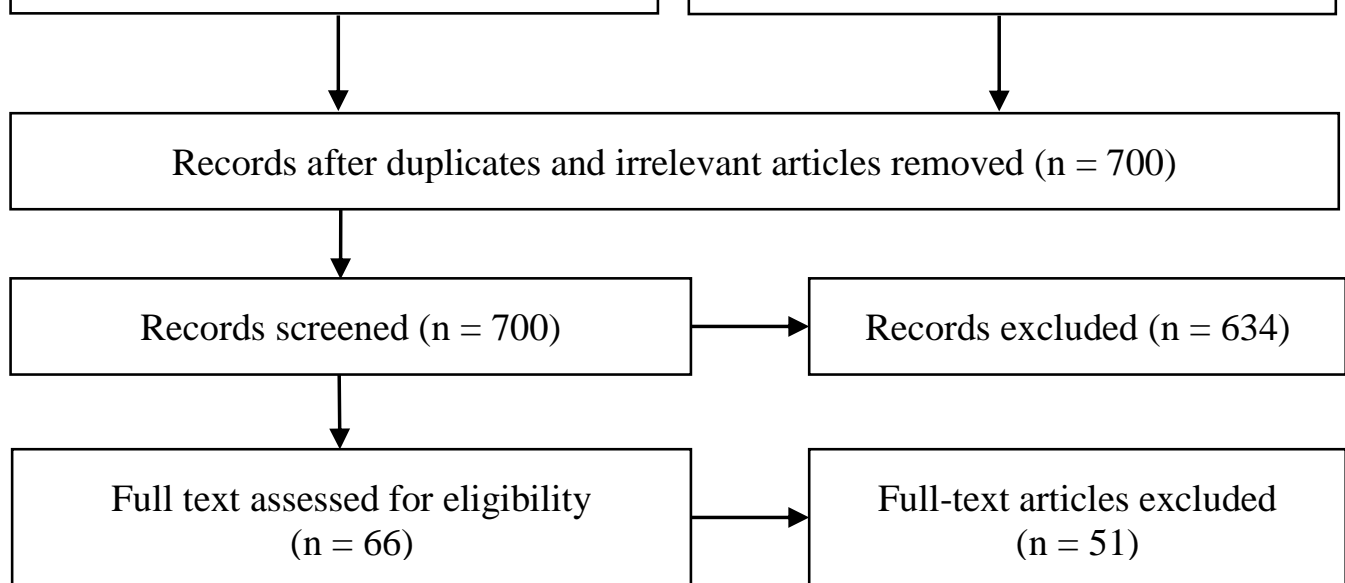

Source: Adapted from Moher et al. (2009)

\section{Figure 1: Flow Diagram - PRISMA}

\section{Data Analysis}

From the thorough database search as described in Figure 1, 15 articles were examined by looking at the abstracts and later, the full texts were evaluated to identify appropriate themes and sub-themes of policy transfer. Qualitative synthesis was performed using thematic analysis which includes three methods namely; identify, analyse, and report patterns of data or (also known as) themes as a valid reflection of entire data set (Braun \& Clarke, 2006; Bree $\&$ Gallagher, 2016). Finally, data were analysed based on typology to create themes and subthemes (Shaffril et al., 2019).

\section{Results and Discussion}

The analysis resulted in five overarching themes to reflect the concept of policy transfer. As presented in Table 3, the five themes include policy transfer definitions, similar terms to represent policy transfer, types of policy actors, policy transfer processes, and policy transfer analysis. These results represent a comprehensive analysis of the current literature published in the domain of policy transfer from all over the world. The main contribution is focused on the core concept of policy transfer regardless of its application in any field.

Worth to note that there were three past studies focused on European policy (Karini, 2017; Dabrowski, Musialkowska, \& Polverari, 2018a; Dabrowski, Musialkowska, \& Polverari, 2018b), two studies originated from policy experience in United States of America - USA (Bauer, 2010; Stone, de Oliveira, \& Pal, 2019), and another two studies from United Kingdom - UK (Keating \& Cairney, 2012; Dolowitz, 2017). The remaining articles were derived from Australia (Walker, 2019), Brazil (de Oliveira \& Pal, 2018), China (Zhang \& $\mathrm{Yu}, 2019$ ), Germany (Barabasch, 2010), Indonesia (Nugroho, Zuiderwijk, Janssen, \& de Jong, 2015), Malaysia (Siddiquee, 2010), Netherlands (Minkman, van Buuren, \& Bekkers, 
2018), and Sweden (Petridou \& Olausson, 2017) with each country had published an article on policy transfer.

In terms of the publication year, three articles were published in 2010 (Barabasch, 2010; Bauer, 2010; Siddiquee, 2010), an article was published in 2012 (Keating \& Cairney, 2012), and in 2015 (Nugroho et al., 2015). Next, three articles were published in 2017 (Dolowitz, 2017; Karini, 2017; Petridou \& Olausson, 2017), followed by four articles published in 2018 (Dabrowski et al., 2018a; Dabrowski et al., 2018b; de Oliveira \& Pal, 2018; Minkman et al., 2018) and three articles published in 2019 (Stone et al., 2019; Walker, 2019; Zhang \& Yu, 2019). These articles $(n=15)$ were included in the review for further thematic analysis. In the case of methodology, four studies employed primary data through qualitative approach (Nugroho et al., 2015; Karini, 2017; Petridou \& Olausson, 2017; Walker, 2019) while the rest applied secondary data as review papers. 
Table 3: The Synthesis of Themes (Policy Transfer - PT)

\begin{tabular}{|c|c|c|c|c|c|c|c|c|c|c|c|}
\hline \multirow{2}{*}{ Authors } & \multicolumn{2}{|c|}{ PT Definition } & \multicolumn{2}{|c|}{ Similar Terms } & \multicolumn{2}{|c|}{ Policy Actor } & \multicolumn{3}{|c|}{ PT Process } & \multicolumn{2}{|c|}{ PT Analysis } \\
\hline & Basic & Exact & Basic & Exact & Basic & Exact & What & How & Where & Approach & Type \\
\hline 1) Barabasch (2010) - Germany & & $\sqrt{ }$ & $\sqrt{ }$ & & $\sqrt{ }$ & & $\sqrt{ }$ & $\sqrt{ }$ & $\sqrt{ }$ & & \\
\hline 2) Bauer (2010) - USA & $\sqrt{ }$ & & & $\sqrt{ }$ & $\sqrt{ }$ & & $\sqrt{ }$ & $\sqrt{ }$ & $\sqrt{ }$ & $\sqrt{ }$ & $\sqrt{ }$ \\
\hline 3) Siddiquee (2010) - Malaysia & $\sqrt{ }$ & & $\sqrt{ }$ & & $\sqrt{ }$ & & $\sqrt{ }$ & & $\sqrt{ }$ & & $\sqrt{ }$ \\
\hline 4) Keating \& Cairney (2012) - UK & $\sqrt{ }$ & & & $\sqrt{ }$ & $\sqrt{ }$ & & $\sqrt{ }$ & $\sqrt{ }$ & $\sqrt{ }$ & $\sqrt{ }$ & $\sqrt{ }$ \\
\hline 5) Nugroho et al. (2015) - Indonesia & & & $\sqrt{ }$ & & $\sqrt{ }$ & & $\sqrt{ }$ & $\sqrt{ }$ & $\sqrt{ }$ & & \\
\hline 6) Dolowitz (2017) - UK & $\sqrt{ }$ & & & $\sqrt{ }$ & $\sqrt{ }$ & & $\sqrt{ }$ & $\sqrt{ }$ & & $\sqrt{ }$ & $\sqrt{ }$ \\
\hline 7) Karini (2017) - Europe & $\sqrt{ }$ & & $\sqrt{ }$ & & $\sqrt{ }$ & & $\sqrt{ }$ & & $\sqrt{ }$ & $\sqrt{ }$ & \\
\hline 8) Petridou \& Olausson (2017) - Sweden & & $\sqrt{ }$ & & $\sqrt{ }$ & & $\sqrt{ }$ & $\sqrt{ }$ & $\sqrt{ }$ & & & \\
\hline 9) Dabrowski et al. (2018a) - Europe & & $\sqrt{ }$ & $\sqrt{ }$ & & & $\sqrt{ }$ & $\sqrt{ }$ & $\sqrt{ }$ & $\sqrt{ }$ & & $\sqrt{ }$ \\
\hline 10) Dabrowski et al. (2018b) - Europe & $\sqrt{ }$ & & $\sqrt{ }$ & & $\sqrt{ }$ & & $\sqrt{ }$ & $\sqrt{ }$ & $\sqrt{ }$ & & \\
\hline 11) de Oliveira \& Pal (2018) - Brazil & $\sqrt{ }$ & & $\sqrt{ }$ & & & $\sqrt{ }$ & & & $\sqrt{ }$ & & \\
\hline 12) Minkman et al. (2018) - Netherlands & & $\sqrt{ }$ & & $\sqrt{ }$ & & $\sqrt{ }$ & $\sqrt{ }$ & $\sqrt{ }$ & & $\sqrt{ }$ & $\sqrt{ }$ \\
\hline 13) Stone et al. (2019) - USA & $\sqrt{ }$ & & $\sqrt{ }$ & & & $\sqrt{ }$ & $\sqrt{ }$ & $\sqrt{ }$ & $\sqrt{ }$ & $\sqrt{ }$ & \\
\hline 14) Walker (2019) - Australia & $\sqrt{ }$ & & $\sqrt{ }$ & & $\sqrt{ }$ & & $\sqrt{ }$ & & $\sqrt{ }$ & $\sqrt{ }$ & \\
\hline 15) Zhang \& Yu (2019) - China & $\sqrt{ }$ & & $\sqrt{ }$ & & & $\sqrt{ }$ & $\sqrt{ }$ & $\sqrt{ }$ & $\sqrt{ }$ & $\sqrt{ }$ & $\sqrt{ }$ \\
\hline
\end{tabular}

Source: Scopus (2020); Emerald Insight (2020) 


\section{Main Findings}

In this section, the discussion revolves around five main themes covering policy transfer definitions similar terms to represent policy transfer, types of policy actors, process of policy transfer, and policy transfer analysis. The first three themes produced another two sub-themes namely; basic or exact explanation on the main theme. Process of policy transfer generated three sub-themes such as what, how, and where the policy transfer took place. Meanwhile, policy transfer analysis was divided into two sub-themes; approach and type of policy transfer. The sub-themes also discussed the component of what is transferred and the degree of transfer. Elaboration on each theme and sub-theme will be enlightened in the following section.

\section{Policy Transfer Definitions}

Since there are many misconceptions regarding the concept of policy transfer, this section elaborates the most important part to describe policy transfer which is the definition. Out of 15 articles, just about four articles (Barabasch, 2010; Petridou \& Olausson, 2017; Dabrowski et al., 2018a; Minkman et al., 2018) provide the exact and detailed definitions of policy transfer. For instance, Barabasch (2010) noted that policy transfer represents government strategies, action plans, guidelines, goals and objectives, as well as rules and regulations. He echoed the policy transfer definition from Page (2000) which focused on three basic questions about (1) who involved, (2) what is transferred, and (3) when it was transferred. On the flip side, Minkman et al. (2018) referred policy transfer as an action-oriented international activity by autonomous policy actors involving either voluntary or coercive policy practices. In the same vein, these four articles agreed to adopt the basic definition by Dolowitz and Marsh (2000): "Policy transfer represents a process in which knowledge about policies, administrative arrangements, or institutions; in one time and/or place is employed in the development of other policies, administrative arrangements, or institutions in another time and/or place" (pp.344). It is widely accepted in layman's words that the concept of policy transfer reflects the use of a policy in a selected country to be 'copied' or 'imitated' in another country whether it is within or between different political context (Petridou \& Olausson, 2017; Dabrowski et al., 2018a).

\section{Similar Terms to Represent Policy Transfer}

Working upon the uncertain context of policy transfer, many scholars interchangeably claimed policy transfer with alternative concepts under various headings from policy borrowing, policy adaptation, policy convergence to lesson drawing (Barabasch, 2010; Bauer, 2010; Petridou \& Olausson, 2017). In some cases, researchers used these terms; policy learning, policy diffusion, benchmarking, and 'best practice' (Keating \& Cairney, 2012; Dolowitz, 2017; Minkman et al., 2018). Over the time, the political theorists attempt to create boundaries against these overlapping terms. Most often, policy transfer is deemed as a part of lesson drawing. However, Rose (1991) was among the first to highlight that lesson drawing is actually based on conscious and voluntary process to decide whether the government adopted a policy from the past or another place. On the other hand, policy transfer is predominantly taking place through coercive manner. Evans (2004) and Bauer (2010) expanded the previous understanding on policy learning and policy transfer by pointing out the fact that policy learning is actually emerged from the process of policy transfer. With the same agreement, Minkman et al. (2018) asserted that policy transfer is a wider concept and policy learning might happen prior to the process of policy transfer or during the later phases. Further, he explained that either the government learn from the other parties before commencing the transfer process or the policy evaluation (after the policy been transferred) may result in 
policy learning. In both ways, policy learning is associated with the implications of successful policy transfer.

\section{Types of Policy Actors}

Drawing upon the work of a number of political scientists, these researchers hardly explained the detailed perspective of policy actors. Most often, when it comes to policy transfer, people assumed that the policy actors are the government and politicians. Nevertheless, six articles give details on the exact roles and responsibilities of policy actors. Interestingly, Minkman et al. (2018) revealed the importance of multiple non-state actors other than the government officials, policymakers, or international governmental organizations such as European Union (EU), World Bank, and United Nations (UN). In particular, the author mentioned the responsibilities of researchers, consultants, or Non-government organization (NGO) as the non-state actors. These three policy groups may act as the initiator of the transfer and provide vast knowledge about policy networks. In this connection, Stone et al. (2019) add values to the current literature on policy actors by introducing the notion of policy entrepreneurs and policy ambassador as transfer agents. The authors defined policy entrepreneurs as public servants consist of lawyers, statisticians, parliamentary researchers, or political advisors. Without a doubt, they possess the power of persuasion while the policy ambassadors refer to the charismatic individuals who are able to fascinate different cultures, speak several languages, and portray diplomatic behaviour to function as negotiator and building bridges across different countries.

\section{Process of Policy Transfer}

This section reflects the policy transfer process through three main policy questions namely; what, how, and where the policy transfer take place. The first criteria (What?) explained the details of the policy transfer occurred especially in terms of the policy transfer process. Next, the criteria (How?) enlightened the readers on the exact process involved in policy transfer such as the mechanism of a government or institution employed to put into practice the 'borrowed' policy or idea. The latter part (Where?) revealed the location or situation which the policy was transferred; either from a country to another country or from private to public institution (Dolowitz, 2017; Stone et al., 2019; Walker, 2019). The merit of the past policy transfer literature, most of the authors in this review discussed the process of policy transfer comprehensively. For instance, Zhang and Yu (2019) conducted a study on the China-Europe Public Administration (CEPA) program. Among other articles, their work was among the most detailed article to explain the process of policy transfer. It has been well pointed out that the initiative to conduct public administrative reform in China had motivated the Chinese government to look both inside and outside of the country to find the best practice. Owing to the good diplomatic ties with European Union (EU) officials, the Chinese government was convinced with the positive governance of EU and agreed to cooperate, and China became the policy importer. The authors listed 12 stages of policy transfer process and eventually, the synchronised role of transfer agents and policy importer were concluded as the most fundamental keys for successful policy transfer.

\section{Policy Transfer Analysis}

With the dawdling progress to straighten out the exact understanding of policy transfer, this concept is remained as inherently complicated (Petridou \& Olausson, 2017; Stone et al., 2019). Specifically, there are many approaches to elaborate on policy transfer analysis yet, the approach and type of transfer; (1) what is transferred and (2) the degree of transferred are the most frequent sub-headings used to reflect policy transfer analysis. To address the policy 
transfer approach, the use of voluntary and coercive continuum was globally accepted. Even though there are attempts to classify the voluntary transfer as lesson drawing and coercive transfer was regarded as policy transfer (Rose, 1991; Petridou \& Olausson, 2017); Dolowitz and Marsh (2012) mapped the policy transfer framework and assessed the reasons of transfer using voluntary and coercive indicators. Hence, a number of researchers in recent years opted to clarify reasons why policy transfer was adopted using both voluntary and coercive measurements. In another angle, instruments (de Oliveira \& Pal, 2018), policies (Bertram et al., 2019), ideas (Nugroho et al., 2015; Minkman et al., 2018), programs (Zhang \& Yu, 2019), and negative lessons (Dabrowski et al., 2018b) are among the elements to elucidate the question of what is transferred. Also, in accordance with the earlier literature on policy transfer and current publications, most scholars (Bauer, 2010; Minkman et al., 2018; Dabrowski et al., 2018b) mutually agreed with four different types of policy transfer such as copying (without modification), emulation (acceptance of a program as the best practice for similar problem), hybridization (combination of elements in several settings), and inspiration (idea which stimulates fresh thinking to address policy problem in host country).

\section{Conclusion}

This systematic review provides a wide array of elements to constitute the practice of policy transfer. In fact, most government had adopted policy transfer as a quick measure to solve policy problems whether they realise it or not. This study is among the spearhead to integrate the fragmented and disconnected past studies on policy transfer. Our findings revealed that most importantly, there were five themes advanced the understanding of policy transfer namely; definitions, similar terms, types of policy actors, process of policy transfer, and policy transfer analysis. By adopting systematic review, possible research gaps and direction for future studies can be drawn towards political scientist, policymakers, and fellow researchers. For instance, political scientist should be aware the basic knowledge of policy transfer before the initiation of transferred policy can be executed. Similarly, the policymakers and researchers should take into account the role of policy actors since the magnitude of change that the transfer agents and the policy importer possess; may determine the effectiveness of the policy in the host country.

With the nature of this systematic review, several recommendations were proposed for future policy studies as follows: First, this study focused on the current literature on policy transfer from 2010 to 2020. This restriction limits the potentials of the original definition and classification of policy transfer from the perspective of historical development. The classical work on policy transfer might have different values and features than the contemporary policy thinking. Second, the inclusion criteria in terms of language and open access perhaps formed the non-exhaustive body of knowledge while missing a number of empirical studies on the topic. For that reason, future studies need to be more careful in selecting the inclusion and exclusion criteria to ensure all relevant resources were gathered extensively. In fact, it is recommended to conduct systematic review on policy transfer in another timeline which is from the early publications on the domain of policy transfer by recognised scholars such as Rose (1991), Wolman (1992), Dolowitz \& Marsh (1996), and Stone (1999); among others.

\section{Acknowledgement}

This research is supported by Ministry of Education, Malaysia's Long-Term Research Grant Scheme (LRGS - 203.PJJAUH.67212003) and USM Fellowship Scheme 2019. 


\section{References}

Barabasch, A. (2010). Methodological and theoretical approaches to the study of governance and policy transfer in vocational education and training. Research in Comparative and International Education, 5(3), 224-236. doi: 10.2304/rcie.2010.5.3.224.

Bauer, J. M. (2010). Learning from each other: promises and pitfalls of benchmarking in communications policy. Info: the Journal of Policy, Regulation and Strategy for Telecommunications, Information and Media, 12(6), 8-20.

Bertram, D., Maleki, A., \& Karsten, N. (2019). Factoring in societal culture in policy transfer design: The proliferation of private sponsorship of refugees. Journal of International Migration and Integration, 253-271. doi: 10.1007/s12134-019-00738-0.

Bramer, W. M., Rethlefsen, M. L., Kleijnen, J., \& Franco, O. H. (2017). Optimal database combinations for literature searches in systematic reviews: a prospective exploratory study. Systematic Reviews, 6(1), 1-12. doi: 10.1186/s13643-017-0644-y.

Braun, V. \& Clarke, V. (2006). Using thematic analysis in psychology. Qualitative Research in Psychology, 3(2), 77-101. doi: 10.1191/1478088706qp063oa.

Bree, R. T., \& Gallagher, G. (2016). Using Microsoft Excel to code and thematically analyse qualitative data: a simple, cost-effective approach. AISHE-J: The All Ireland Journal of Teaching and Learning in Higher Education, 8(2), 2811-28114.

Crossley, M. (2019). Policy transfer, sustainable development and the context $\mathrm{s}$ of education. Compare: A Journal of Comparative and International Education, 49(2), 175-191. doi: 10.1080/03057925.2018.1558811.

Dabrowski, M., Musialkowska, I., \& Polverari, L. (2018). EU-China and EU-Brazil policy transfer in regional policy. Regional Studies, 52(9), 1169-1180.

Dabrowski, M., Musialkowska, I., \& Polverari, L. (2018). Introduction: drawing lessons from international policy-transfer initiatives in regional and urban development and spatial planning. Regional Studies, 52(9), 1165-1168. doi: 10.1080/00343404.2018.1462490.

de Oliveira, O. P., \& Pal, L. A. (2018). New frontiers and directions in policy transfer, diffusion and circulation research: Agents, spaces, resistance, and translations. Revista de Administracao Publica, 52(2), 199-220. doi: 10.1590/0034-761220180078.

Dolowitz, D. P. (2017). Transfer and learning: one coin two elements. Novos Estudos CEBRAP, 36(1), 35-56. doi: 10.25091/s0101-3300201700010002.

Dolowitz, D., \& Marsh, D. (1996). Who learns what from whom: a review of the policy transfer literature. Political Studies, 44(2), 343-357. doi: 10.1111/j.14679248.1996.tb00334.x.

Dolowitz, D. P., \& Marsh, D. (2000). Learning from abroad: The role of policy transfer in contemporary policy-making. Governance, 13(1), 5-23. doi: 10.1111/09521895.00121.

Dolowitz, D. P., \& Marsh, D. (2012). The future of policy transfer research. Political Studies Review, 10(3), 339-345. doi: 10.1111/j.1478-9302.2012.00274.x.

Emerald Insight. (2020). Welcome to Emerald Journals. Retrieved January 17, 2020 from https://www.emerald.com/insight/content/journals.

Evans, M. (2004). Policy transfer in global perspective. New York, NY: Ashgate Publishing.

Freestone, R., \& James, P. (2019). Learning from LA: Australian responses to Los Angeles urbanism 1910-1960. Journal of Planning History, 18(1), 44-65. doi: $10.1177 / 1538513218755497$.

Jones, T., Blaustein, J., \& Newburn, T. (2019). Researching cross-national policy mobilities in crime control. Criminology \& Criminal Justice, 1-19. doi: $10.1177 / 1748895819864627$. 
Karini, A. (2017). Facilitators and Constraints of Policy Learning for Administrative Capacity in the Western Balkans. NISPAcee Journal of Public Administration and Policy, 10(2), 73-92. doi: 10.1515/nispa-2017-0012.

Keating, M., \& Cairney, P. (2012). Introduction: policy-making, learning and devolution. Regional \& Federal Studies, 22(3), 239-250. doi: 10.1080/13597566.2012.688269.

Minkman, E., van Buuren, M. W., \& Bekkers, V. J. J. M. (2018). Policy transfer routes: an evidence-based conceptual model to explain policy adoption. Policy Studies, 39(2), 222-250. doi: 10.1080/01442872.2018.1451503.

MIT Libraries. (2020). Database Search Tips: Truncation. Retrieved January 19, 2020 from https://libguides.mit.edu/c.php?g=175963\&p=1158679.

Moher, D., Liberati, A., Tetzlaff, J., \& Altman, D. G. (2009). Preferred reporting items for systematic reviews and meta-analyses: the PRISMA statement. Annals of Internal Medicine, 151(4), 264-269. doi: 10.1371/journal.pmed.1000097.

Nugroho, R. P., Zuiderwijk, A., Janssen, M., \& de Jong, M. (2015). A comparison of national open data policies: Lessons learned. Transforming Government: People, Process and Policy, 9(3), 286-308. doi: 10.1108/TG-03-2014-0008.

Othman, I. W. (2019). Signifikasi struktur sosial keluarga dan hubungan persahabatan dalam mempengaruhi pengalaman ekspatriasi ahli akademik universiti awam Malaysia. International Journal of Politics, Public Policy and Social Work, 1(3), 1413.

Petridou, E., \& Olausson, P. M. (2017). Policy entrepreneurship and policy transfer: flood risk governance in Northern Sweden. Central European Journal of Public Policy, 11(1), 1-12. doi: 10.1515/cejpp-2016-0028.

Rose, R. (1991). What is lesson-drawing?. Journal of Public Policy, 11(1), 3-30. doi: 10.1017/S0143814X00004918.

Scopus. (2020). Scopus Data: Curated. Connected. Complete. Retrieved from https://www.elsevier.com/_data/assets/pdf_file/0017/114533/Scopus_GlobalResearc h_Factsheet2019_FINAL_WEB.pdf.

Shaffril, H. A. M., Samah, A. A., Samsuddin, S. F., \& Ali, Z. (2019). Mirror-mirror on the wall, what climate change adaptation strategies are practiced by the Asian's fishermen of all?. Journal of Cleaner Production, 232, 104-117. doi: 10.1016/j.jclepro.2019.05.262.

Siddiquee, N. A. (2010). Managing for results: lessons from public management reform in Malaysia. International Journal of Public Sector Management, 23(1), 38-53. doi: 0.1108/09513551011012312.

Stone, D. (1999). Learning lessons and transferring policy across time, space and disciplines. Politics, 19(1), 51-59. doi: 10.1111/1467-9256.00086.

Stone, D., Porto de Oliveira, O., \& Pal, L. A. (2019). Transnational policy transfer: the circulation of ideas, power and development models. Policy and Society, 1-18. doi: 10.1080/14494035.2019.1619325.

Walker, C. K. (2019). Policy transfer in a corporatist context: Agents, adjustments and continued innovation. Public Policy and Administration, 34(3), 308-328. doi: 10.1177/0952076718754617.

Wolman, H. (1992). Understanding cross national policy transfers: The case of Britain and the US. Governance, 5(1), 27-45. 10.1111/j.1468-0491.1992.tb00027.x.

Zainol, N. A. M., Jusop, A. Z., Ridzuan, A. A., \& Kamaruddin, S. (2019). Managing Malaysian Border: The Challenges and Prospects in Maintaining Security. 
International Journal of Politics, Public Policy and Social Work, 1(3), 1-13. doi: 10.35631/ijppsw.13001.

Zhang, Y., \& Yu, X. (2019). Policy transfer: the case of European Union-China cooperation in public administration reform. International Review of Administrative Sciences, 118. doi: 10.1177/0020852319841427. 